\title{
Mitochondrial Structure Studied by High Voltage Electron Microscopy of Thick Sections of Candida utilis
}

\author{
By M. T. DAVISON AND P. B. GARLAND \\ Department of Biochemistry, Medical Sciences Institute, \\ University of Dundee, Dundee DDI $4 H N$
}

(Received 7 April 1975; revised 4 June 1975)

\begin{abstract}
SUMMAR Y
Mitochondrial structure in yeast cells under various physiological conditions has been studied by high voltage electron microscopy of sections that are 0.5 to $2 \cdot 0 \mu \mathrm{m}$ thick. Such thick sections of the yeast Candida utilis had a small number of long, branched tubular mitochondria per cell. The mitochondria extended into cell buds and unseparated daughter cells. It was apparent from parallel studies with thin sections that most of the rounded mitochondrial profiles viewed in thin sections should not be interpreted as being numerous small individual mitochondria. Attempts to study thick sections of the yeasts Saccharomyces cerevisiae and Schizossaccharomyces pombe were frustrated by poor contrast.
\end{abstract}

\section{INTRODUCTION}

Copper deficiency in mice results in the appearance of giant mitochondria in the liver (Suzuki, 1969; Dallman \& Goodman, 1970). Electron microscopy of thin (about $75 \mathrm{~nm}$ ) sections of Candida utilis apparently showed, in addition, that copper deficiency caused replacement of numerous rounded mitochondria by a smaller number of much enlarged mitochondria, or giant mitochondria (Davison, Downie \& Garland, I972; Keyhani, 1973). However, yeast mitochondria can be tubular (Yotsuyanagi, 1955; Kawakami, 196I), and tubular mitochondria repeatedly crossing the plane of a thin section would appear as numerous individual mitochondrial profiles. Furthermore, if these tubular mitochondria then swelled, their appearance in thin section would reveal fewer but much larger mitochondrial profiles. To settle whether the typical mitochondrial morphology usually deduced from thin sections is in error, two techniques are available. One is serial sectioning and reconstruction by model building, and was used to demonstrate mitochondrial morphology in yeasts by Keddie \& Barajas (1969), who reported that there were only one to four large branched mitochondria per cell. The other technique is high voltage electron microscopy (h.v.e.m.) of thick sections. We have used this latter method for studying the mitochondrial morphology of the yeast $C$. utilis. It is concluded that inspection of single thin sections leads to quite erroneous interpretations of mitochondrial size and number. Examination of thick sections by h.v.e.m. provides a simpler and faster method of inspecting mitochondrial morphology than does serial sectioning, and permits many samples to be studied. We describe our experience with this technique. A preliminary report has been published (Davison \& Garland, 1974). We also describe the effects of copper and other nutrient limitations on the electron microscopic appearance of $C$. utilis. 


\section{METHODS}

Candida utilis strain 193, from the National Collection of Yeast Cultures, Nutfield, Surrey, was grown in continuous culture with glycerol limitation as described by Light \& Garland (197I), or with sulphate limitation (Haddock \& Garland, 197I), or with copper limitation (Downie \& Garland, 1973). The dilution rate of the chemostat was $0.2 \mathrm{~h}^{-1}$ unless otherwise stated. For some experiments batch culture was used; the medium was $500 \mathrm{ml}$ of the defined medium described by Light \& Garland (I97I) for glycerol-limited continuous culture. Cells were harvested by centrifugation and washed twice with distilled water. Sphaeroplasts, used for histochemical staining for cytochrome oxidase, were prepared by the use of snail gut enzyme (Light \& Garland, 197I) and washed twice in 0.22 M-sucroseO.I M-potassium phosphate buffer (phosphate-sucrose buffer), $\mathrm{pH} 7 \cdot 4$.

Fixation of sphaeroplasts for electron microscopy was effected by incubation for $2 \mathrm{~h}$ in $2.5 \%(\mathrm{v} / \mathrm{v})$ glutaraldehyde in phosphate-sucrose buffer $\mathrm{pH} 7.4$ at $4{ }^{\circ} \mathrm{C}$, followed by two washes in the phosphate-sucrose buffer to remove glutaraldehyde. Treatment of sphaeroplasts for visualization of cytochrome oxidase by the $3,3^{\prime}$-diaminobenzidine method of Seligman et al. (1968) was as follows. Sphaeroplasts from $0.4 \mathrm{~g}$ wet wt cells were incubated for 20 to $45 \mathrm{~min}$ at room temperature in $7.0 \mathrm{ml}$ of phosphate-sucrose buffer containing $3,3^{\prime}$ diaminobenzidine $(0.5 \mathrm{mg} / \mathrm{ml})$ and $\mathrm{H}_{2} \mathrm{O}_{2}(30 \mathrm{~mm})$. A controlincubation was set up by adding the sphaeroplasts to $7.0 \mathrm{ml}$ of phosphate-sucrose buffer containing I mM-KCN, adding $\mathrm{H}_{2} \mathrm{O}_{2}$ and diaminobenzidine after $\mathrm{I} 0 \mathrm{~min}$, and continuing the incubation for a further 20 to $45 \mathrm{~min}$. The sphaeroplasts from both test and control incubations were then washed three times in phosphate-sucrose buffer at $4{ }^{\circ} \mathrm{C}$, followed by fixation in I \% $(\mathrm{w} / \mathrm{v})$ osmium tetroxide in phosphate-sucrose buffer at $4{ }^{\circ} \mathrm{C}$. The fixed sphaeroplasts were then washed twice in phosphatesucrose buffer, dehydrated with an ethanol/water series, and embedded in Spurr's (1969) resin.

Preparation of yeast cells for lead-citrate staining was carried out as follows. Cells were fixed in $2.5 \%(\mathrm{v} / \mathrm{v})$ glutaraldehyde in $0 . \mathrm{I}$ M-sodium cacodylate buffer $\mathrm{pH} 7.0$ at $4{ }^{\circ} \mathrm{C}$ for $2 \mathrm{~h}$. The cells were then placed in freshly made $2 \%(\mathrm{w} / \mathrm{v})$ potassium permanganate solution at $4{ }^{\circ} \mathrm{C}$ for $2 \mathrm{~h}$, followed by a further $2 \mathrm{~h}$ in a fresh solution at room temperature. Next, the cells were washed at least five times with distilled water and placed in a solution containing $\mathrm{I} \%$ $(\mathrm{w} / \mathrm{v})$ potassium dichromate and I $\%(\mathrm{w} / \mathrm{v})$ uranyl acetate for $2 \mathrm{~h}$ at $4{ }^{\circ} \mathrm{C}$. The cells were then washed several times with distilled water, embedded in agar, cut into small blocks, dehydrated with ethanol and embedded in Spurr's resin.

Sections 0.5 to $2 \cdot 0 \mu \mathrm{m}$ thick (i.e. thick sections) were cut with glass knives using a Reichert $\mathrm{OM} \mathrm{U}_{3}$ ultramicrotome. To avoid lateral tears (Favard \& Carasso, 1973) which osbcure detail when the sections are viewed, two or three sections about $70 \mu \mathrm{m}$ thick (i.e. thin sections) were interposed between thick sections. Sections were stretched by heat, using a modified battery-operated gas lighter in preference to chloroform vapour which caused the thicker sections to curl. To prevent the thick sections from falling off the grids during staining and washing procedures, and during viewing, it was necessary first to flame the grids until clean and dip them in a solution of Sellotape adhesive in chloroform; alternatively, sections could be mounted on collodion-coated copper grids. Sections were stained by immersion in freshly prepared lead citrate solution (Reynolds, 1963) diluted approximately 30-fold in freshly prepared $0.01 \mathrm{M}-\mathrm{NaOH}$, and afterwards washed by dipping in $0.05 \%(\mathrm{v} / \mathrm{v})$ nitric acid and then in several changes of distilled water.

Thin sections were viewed with an AEI 80I electron microscope. Thick sections were viewed with an AEI EM7 high voltage electron microscope at the Department of Metallurgy and Materials Science, Imperial College, London. 


\section{RESULTS}

Electron microscopy of thin sections of C. utilis grown in continuous culture under a variety of growth limiting conditions

Figures I to 5 show electron micrographs of thin sections of $C$. utilis cells grown in continuous culture where the growth-limiting nutrient was glycerol (Fig. r), iron (Fig. 2), sulphate (Figs. 3 and 4) and copper (Fig. 5). These Figures may be used as points of reference for comparison with thick sections. They illustrate the cell and mitochondrial morphologies resulting from growth conditions that produce cells with well-documented alterations in the mitochondrial respiratory chain and associated energy conservation mechanisms (Garland, 1970; Light \& Garland, I97I; Haddock \& Garland, I97I ; Light, I972; Keyhani \& Chance, I97I; Downie \& Garland, 1973).

The structure of glycerol-limited $C$. utilis shown by electron microscopy of thin sections stained with lead citrate (Fig. I) shows a familiar picture for aerobically grown yeasts, there being easily-discernible mitochondrial profiles that are mainly round or oval and about 0.1 to $0.3 \mu \mathrm{m}$ in diameter. Usually there are 6 to Io such mitochondrial profiles per section. Neither iron limitation (Fig. 2) nor sulphate limitation (Fig. 3) caused any noticeable change in mitochondrial structure. Iron-limited cells showed vacuoles and thick walls, presumably due to excess carbon being available. Sulphate-limited cells showed similar changes, although thickening of the cell wall was less marked than in iron-limited cells. Aeration of sulphate-limited cells for several hours, a treatment that restores site I energy conservation (Haddock \& Garland, I97I), did not significantly alter cellular or mitochondrial structure as shown by electron microscopy of thin sections. However, if sulphate-limited cells were aerated in I mM-sulphate, a treatment that results in the appearance of a cyanideinsensitive respiratory chain (Haddock \& Garland, 197I), the cells also exhibited altered mitochondrial morphology. This is shown in Fig. 4, where it is seen that the mitochondrial profiles, which are larger but fewer per cell, are well-filled with cristae in contrast to the relative scarcity of cristae in the mitochondria of glycerol-limited cells (Fig. I).

Growth of either wild-type $C$. utilis or the copper-independent variant in copper-deficient media resulted in cells where mitochondrial profiles became irregular in outline, enlarged and fewer per cell (Fig. 5), as described by Davison et al. (1972) and Keyhani (1973).

\section{Electron microscopy of thick sections of $C$. utilis stained with lead citrate}

For Figs. 6, 7 and 8, photograph pairs were taken at $\pm 4^{\circ}$ tilt and should be examined with the aid of a stereoscopic viewer. An oval-shaped $C$. utilis cell is about 3 to $4 \mu \mathrm{m}$ long and I to $2 \mu \mathrm{m}$ in diameter, and thus except for cell buds even the thickest sections $(2 \mu \mathrm{m})$ are unlikely to include a whole unsectioned cell. Nevertheless, there is sufficient depth in the sections to permit considerable overlap of subcellular organelles. Contrast in thick sections is affected not only by the amount and nature of overlaying material, but also in a more specific manner by cylindrical or tubular objects (see below) such as mitochondria. A tubular mitochondrion running vertically through the section would be expected to show enhanced contrast of its membranes, presenting a well-marked profile resembling those seen in thin sections, whereas a tubular mitochondrion lying with its long axis parallel to the plane of the section would be relatively less well contrasted.

Figure 6 shows stereo-pair photographs of a $1 \mu$ m-thick section of chemostat-grown, glycerol-limited $C$. utilis stained with lead citrate. The cell is budding, and a tubular mitochondrion about 4 to $5 \mu \mathrm{m}$ long is seen extending from the parent cell through a ring-shaped 

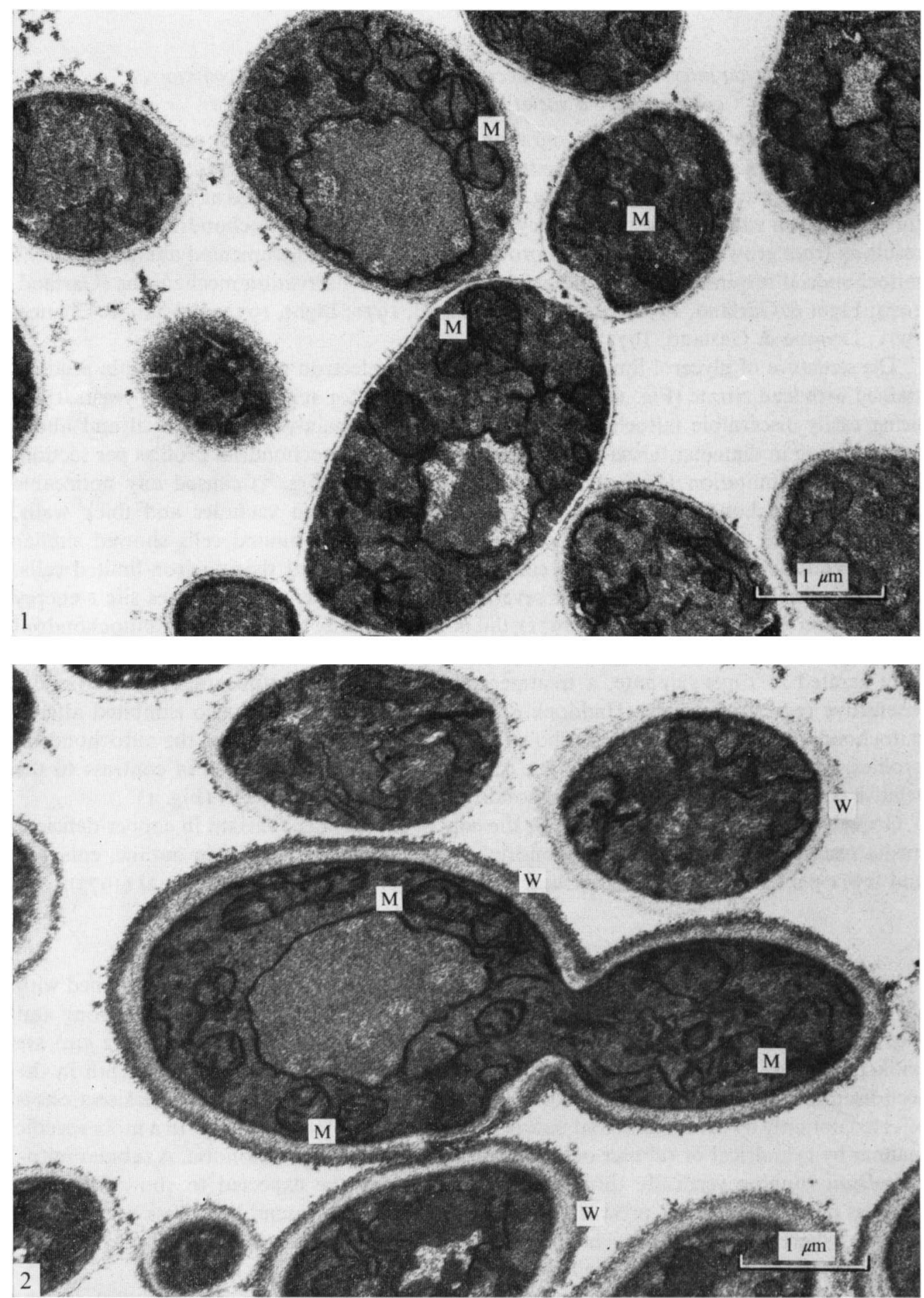

Fig. I. Thin section of chemostat-cultured glycerol-limited C. utilis cells, stained with lead citrate, showing several mitochondrial profiles $(M)$ per cell.

Fig. 2. Thin section of chemostat-cultured iron-limited C. utilis cells, stained with lead citrate, showing mitochondrial (M) and thickened walls (W). 
exit in the cell wall into the daughter cell. There is insufficient detail in the structure in the lower part of the cell (i.e. nearer the bottom of the photograph) to decide whether they are mitochondria or not. However, it seems likely that more than one tubular mitochondrial structure is extruding into the cell bud, and one of these terminates in a distinct mitochondrial profile, suggesting that it is turned out of the plane of the section. Long tubular mitochondria were present in all cells examined, and all cells had some branched tubes. Figure 7 shows a I $\mu$ m-thick section of a C. utilis cell from the exponential growth phase of a batch culture in glycerol medium. The cell is budding, and not more than two long mitochondrial tubes can be identified in the parent cell; one tube runs around the top-right periphery of the cell and turns out of the section at the top, whereas the other is branched, and two of the branches appear to join up again to make a ring.

The identification of mitochondria in lead citrate-stained thick sections was made on the expectation that there would be cytoplasmic structures of suitable dimensions to account for the structures seen in the better-documented thin sections. Further evidence that these tubular structures are indeed mitochondria came from the presence of what appeared to be cristae seen running in the long axis of the tubular mitochondria, and showing themselves in a more familiar view when the mitochondrial tube turned to leave the section and gave a typical mitochondrial profile as seen in thin section. We were unable to obtain satisfactory contrast with thick sections of iron- or sulphate-limited cells, because of interference by vacuoles.

\section{Electron microscopy of thick sections of sphaeoplasts of C. utilis stained by the diaminobenzidine method}

3,3'-Diaminobenzidine is oxidized by cytochrome $c$ and cytochrome $c$ oxidase (EC. I.9.3. I) to yield an osmiophilic deposit on the outer surface of the inner mitochondrial membrane (Seligman et al. 1968). Although diaminobenzidine can be used for a histochemical localization of other haemoproteins, such as peroxidase (EC. I.II.I.7) and catalase (EC. I.II.I.6), Keyhani (1972) has shown by the use of normal and copper-deficient $C$. utilis that cytochrome $c$ oxidase is responsible for the staining of the inner mitochondrial membrane. We have therefore used this histochemical technique because of the advantages offered by its specificity and, particularly important for thick sections, its high contrast. Figure 8 shows a stereo-pair of photographs of a $2 \mu \mathrm{m}$-thick section of a sphaeroplast of $C$. utilis taken from the stationary phase of a batch culture in glycerol medium. A single long tubular mitochondrion, looped back on to itself, is clearly indentifiable. The cristae are preferentially stained, and run along the length of the tube. There are also several uniformly stained round structures which show no evidence of cristal structure; they are presumably microbodies or peroxysomes (Osumi et al. 1974). Figure 9 shows a thick section of a $C$ utilis sphaeroplast from a glycerol-limited chemostat culture. There were probably three or four separate stretches of mitochondrial tube in this section, though it is possible that they joined with each other outside the section.

\section{Electron microscopy of thick sections of copper-deficient C. utilis cells}

Figure Io shows the structure of the copper-independent variant of C. utilis grown in copper-deficient glycerol-limited continuous culture. Despite the poor contrast, the mitochondrial structures have highly irregular outlines. 

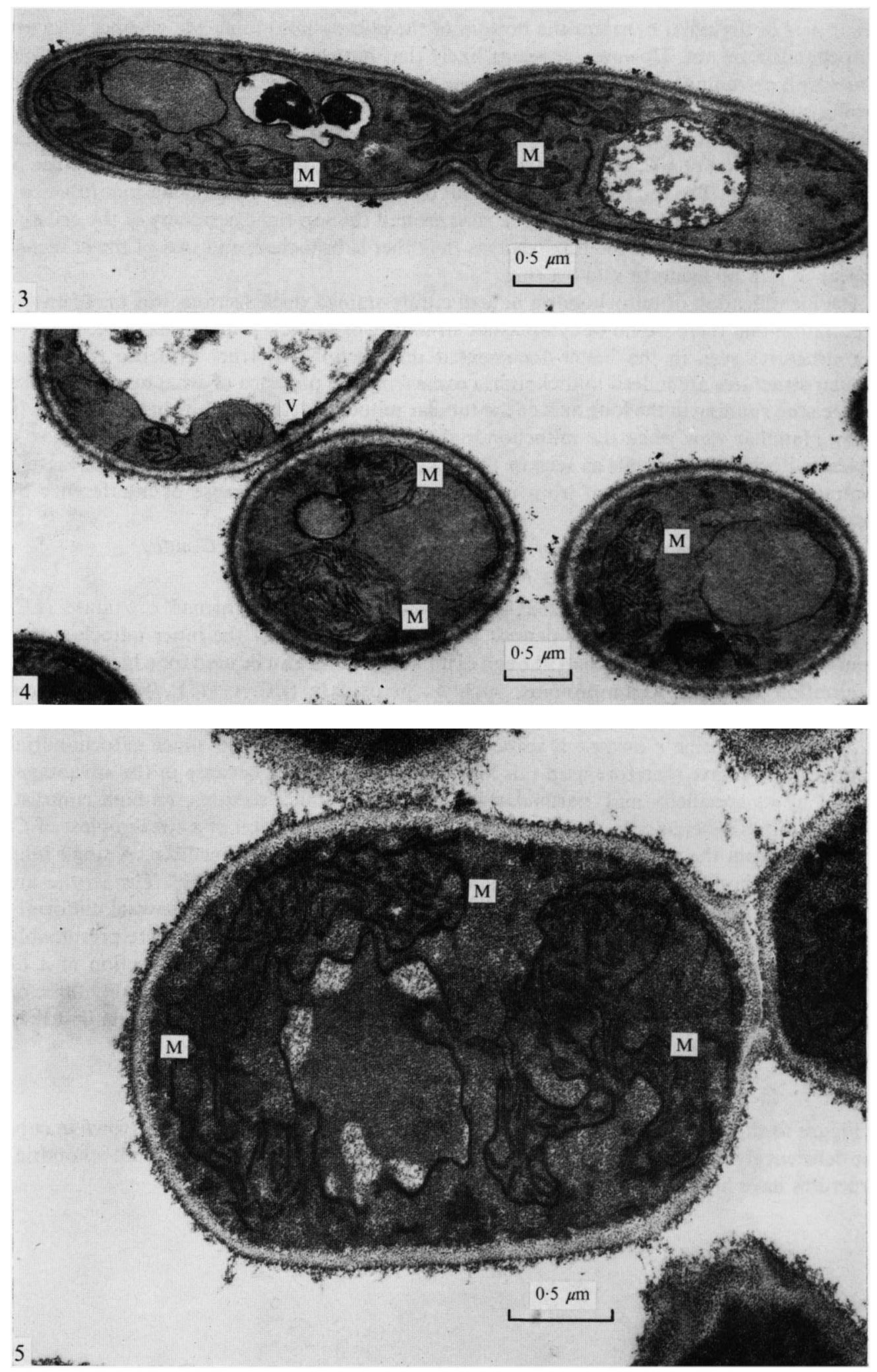

Figs. 3-5. For legend see opposite page. 


\section{The effect of growth conditions on mitochondrial morphology}

Examination of thick sections showed that branched tubular mitochondria were characteristic of $C$. utilis grown in glycerol-limited continous culture at dilution rates varying from 0.2 to $0.6 \mathrm{~h}^{-1}$, or grown in batch culture in glycerol medium and sampled during exponential growth or stationary phases. Variations of morphology related to growth rate or growth phase (Yotsuyanagi, 1955) were not seen.

The number of mitochondrial profiles per cell in thick section

If the several rounded mitochondrial profiles seen in thin section were indeed separate mitochondria, then the number of separate mitochondrial structures observed in thick section should increase over that in thin section. Conversely, if the several profiles seen in thin section were parts of one or two longer branched mitochondria, then the number of separate mitochondrial structures in thick section should decrease. The second of these two possibilities is favoured by the thick sections shown in Figs. 6 to 9, and it is not difficult to envisage how a thin section across such cells could show mitochondrial profiles that are sections across the branched tubular mitochondria. Occasionally, a thin section might by chance run down the long axis of a tubular mitochondrion, and an example of this is shown in Fig. II. However, we have also seen in thick sections the opposite situation, of numerous small separate mitochondrial structures (Fig. I2). It is conceivable that these mitochondrial structures (Fig. I2) communicated in the cell outside the section. Alternatively they may indeed represent separate mitochondria, perhaps related to a specific stage of the cell cycle. We are exploring this latter possibility by serial section of $C$. utilis at different cell cycle stages.

\section{Scanning transmission electron microscopy of thick sections of C. utilis}

We have made a limited study of the use of scanning transmission electron microscopy of thick sections of $C$. utilis. Figure I 3 shows the result with a $0.5 \mu \mathrm{m}$ thick section of a $C$. utilis sphaeroplast from the same culture as that shown in Fig. 8, and stained by the diaminobenzidine procedure. A single long tubular mitochondrion is seen, about $6 \mu \mathrm{m}$ long. Clearly a thin section in a different plane would show three round mitochondrial profiles that in fact were all sections through the same tubular structure. The contrast in this $0.5 \mu \mathrm{m}$ thick section taken at an accelerating voltage of $100 \mathrm{kV}$ was very similar to that obtained by high voltage electron microscopy at 400 to $500 \mathrm{kV}$ with a $2 \mu$ m-thick section (Fig. 8). The scanning transmission technique did not give as satisfactory stereoscopic viewing as did the high voltage technique. This may be due in part to the 'top-bottom effect' described by Gentsch, Gilde \& Reimer (1974).

\section{DISCUSSION}

Although mitochondrial size, shape and number in microbes used often to be estimated from studying random thin sections of cells, this practice has now been thoroughly discredited by the use of serial sections and reconstruction (e.g. Keddie \& Barajas, 1969; Arnold et al. 1972;

Fig. 3. Thin section of chemostat cultured sulphate-limited C. utilis cell stained with lead citrate. M, mitochondria.

Fig. 4. Lead citrate-stained thin section of chemostat-cultured sulphate-limited $C$. utilis cells after an overnight sulphate-recovery treatment with I $\mathrm{mM}$ sulphate (see Haddock \& Garland, 1971). Numerous cristae occur in the mitochondria (M) and a typical large vacuole (V) is shown in one cell.

Fig. 5. Thin section of copper-deficient variant cells of $C$. utilis stained with lead citrate, showing irregular shaped mitochondrial profiles (M). 

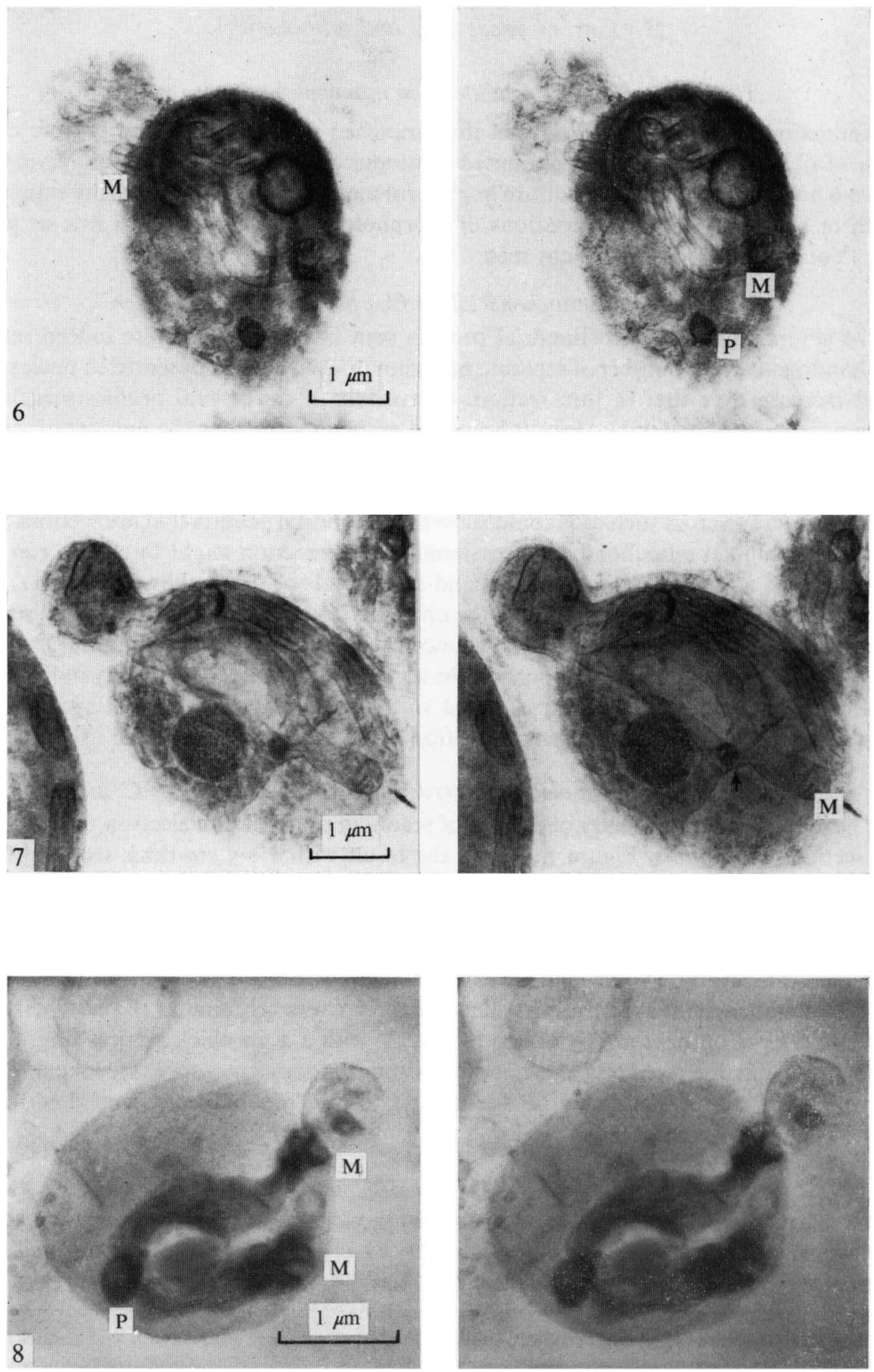

Fig. 6. Stereo-pair of a lead citrate stained thick section ( $\mathrm{I} \mu \mathrm{m})$ of a chemostat-cultured glycerollimited $C$. utilis cell, cultured at a dilution rate of $0.6 \mathrm{~h}^{-1}$. The accelerating voltage was $1000 \mathrm{kV}$. Two tubular mitochondria (M) are seen, one 4 to $5 \mu \mathrm{m}$ long, and a peroxysome (P).

Fig. 7. Stereo-pair of a lead citrate-stained thick section (I $\mu \mathrm{m})$ of a batch-cultured $C$. utilis cell harvested from a glycerol-defined medium in exponential growth phase. The accelerating voltage was $1000 \mathrm{kV}$, tilt $\pm 6^{\circ}$. The section shows the cut end of a branched tubular mitochondrion (M) with cristae in lumen and a branch point (arrow).

Fig. 8. Stereo-pair of a thick section $(2 \mu \mathrm{m})$ of a batch cultured C. utilis sphaeroplast harvested in stationary phase from a glycerol-defined medium and stained with $3,3^{\prime}$-diaminobenzidine and osmium tetroxide. The accelerating voltage was $500 \mathrm{kV}$. The section shows a tubular mitochondrion with two cuts ends (M) and cristae which run along the length of the mitochondria. The darkly 
Hoffmann \& Avers, 1973; Osafune, 1973; Atkinson, John \& Gunning, 1974; Burton \& Moore, 1974). One cannot predict from random thin sections whether serial sections and reconstruction will show numerous individual mitochondria or a single large branched mitochondrion per cell, or situations intermediate between these extremes. For instance, Keddie \& Barajas (1969) demonstrated that the numerous rounded mitochondrial profiles seen in single thin sections of the yeast Pityosporum orbiculare were part of one to four mitochondria per cell, whereas in Trichoderma viride conidia Rosen et al. (1974) showed that the numerous mitochondrial profiles of a thin section mostly corresponded to individual small mitochondria. These latter authors also emphasized that the constrictions of mitochondrial profiles often seen in thin sections should not be interpreted, as they often are, as indicating mitochondrial division.

High voltage electron microscopy of thick sections offers a convenient alternative to serial sectioning and reconstruction for studying mitochondrial morphology. There are however, limitations and a critical account has been given by Glauert (1974). First, high voltage instruments are not commonplace. Secondly, there must be sufficient contrast, as stressed by Weibull (1974) in his study of the yeast Trichosporon cutaneum. Although we have achieved good resolution and contrast with $C$. utilis, we have so far failed to do so with thick sections of S. cerevisiae or Schizosaccharomyces pombe. Thirdly, the use of thick sections loses some of its attraction if the cell under study is so much larger than the thickness of the section that only a small slice of the cell is studied. Fourthly, the interpretation of overlapping structures is difficult. However, our results show that high voltage electron microscopy has some advantages for studying mitochondrial morphology. Given a small yeast such as $C$. utilis, with good contrast from the staining procedures, then many cells from a variety of culture conditions can be studied fairly rapidly; although the information on mitochondrial morphology given by this method may lack some of the stereological precision of serial sectioning and reconstruction, it is nevertheless a considerable advance over that obtained from random thin sections. The study of the relationship between cell division and mitochondrial division in the cell cycle in yeasts, and the effects of mutations and inhibitors affecting one or the other, may well be valuable applications of the high voltage technique to thick sections.

Reconstruction may be possible from serial thick sections. Provided that the requirement (Favard \& Carosso, 1973) for cutting, say, two thin sections between each thick section did not prevent alignment and continuity, then not more than five sections each $\mathrm{I} \cdot 0 \mu \mathrm{m}$ thick would encompass virtually all yeast cells, and give a resolution that might be adequate for answering some of the questions concerning mitochondrial division.

Our studies of the way mitochondrial structure varies with growth conditions illustrate only too well the pitfalls of interpreting from random thin sections. For instance, it has been concluded that copper deficiency in C. utilis reduces the number of mitochondria per cell (Davison et al. 1972; Keyhani, 1973). Yet it is clear from our studies of thick sections (e.g. Figs. 6 to 8) that swelling of the branched tubular mitochondrial structure would of necessity reduce the number of separate mitochondrial profiles per thin section but increase their area, as observed in Fig. 6.

We are deeply indebted to Professor P. R. Swann of the Department of Metallurgy, Imperial College of Science and Technology, London, for access to the A.E.I. EM7 high voltage electron microscope, and to Dr E. P. Butler, Mr J. Woodall, Mr R. Doole and Mr W. Bishop for advice and technical help. Support for this work was provided by the Medical Research Council. We are grateful to Mrs E. Lloyd-Davies for her co-operation, and to 

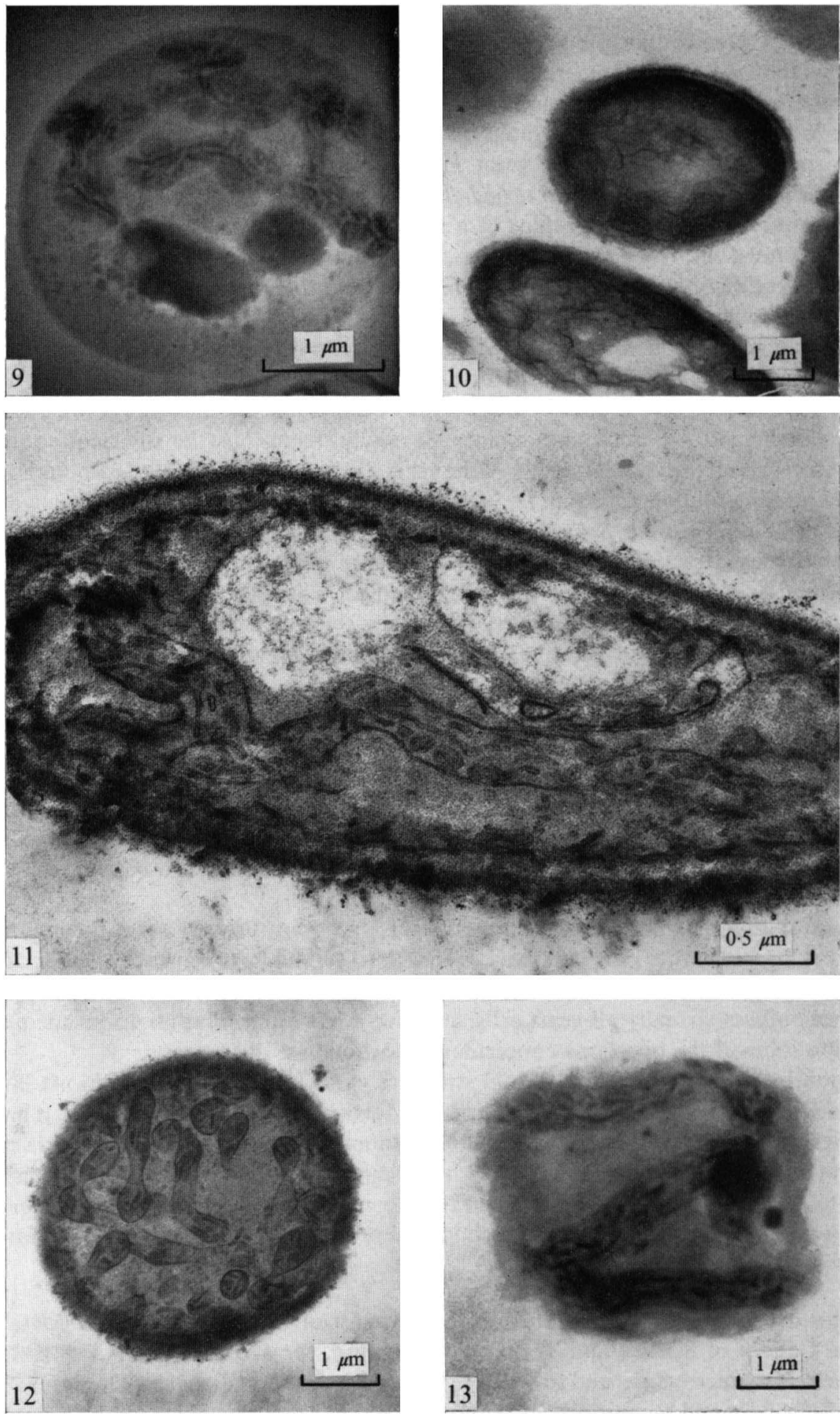

Figs. 9-13. For legend see opposite page. 
Margaret Black and David Coutie for technical assistance. We are also grateful to Jeol (U.K.) Ltd, for the use of the JEM IooC electron microscope with scanning transmission (STEM) attachment.

\section{REFERENCES}

Arnold, C. G., Schimmer, O., Schotz, F. \& Bathelt, H. (1972). Die Mitochondrien von Chlamydomonas reinhardii. Archiv für Mikrobiologie 81, 50-67.

Atrinson, A. E., John, P. C. L. \& Gunning, B. E. S. (1974). The growth and division of the single mitochondrion and other organelles during the cell cycle of Chlorella studied by quantitative stereology and three dimensional reconstruction. Protoplasma 81, 77-109.

Burton, M. D. \& MoORE, J. (1974). The mitochondrion of the flagellate Polytomella agilis. Journal of Ultrastructure Research 48, 4I4-419.

Dallman, P. R. \& Goodman, J. R. (1970). Enlargement of mitochondrial compartment in iron and copper deficiency. Blood 35, 496-505.

Davison, M. T., Downie, J. A. \& Garland, P. B. (1972). Giant mitochondria in iron- or copper-deficient Candida utilis. Biochemical Journal 129, 46-47P.

Davison, M. T. \& GaRLAND, P. B. (1974). The intracellular morphology of yeast mitochondrial membranes: studies with high voltage electron microscopy. Proceedings of the Society for General Microbiology I, 4I.

Downie, J. A. \& Garland, P. B. (1973). An antimycin-A and cyanide-resistant variant of Candida utilis arising during copper limited growth. Biochemical Journal 134, 105I-I06I.

Favard, P. \& Carasso, N. (1973). The preparation and observation of thick biological sections in the high voltage electron microscope. Journal of Microscopy 97, 59-81.

GarLAND, P. B. (1970). A biochemical application of continuous culture: energy conservation in Torulopsis utilis. Biochemical Journal 118, 329-339.

GeNTSCH, P., GiLDE, H. \& Reimer, L. (1974). Measurement of the top-bottom effect in scanning transmission electron microscopy of thick amorphous sections. Journal of Microscopy 100, 81-92.

Glauert, A. M. (1974). The high voltage electron microscope in biology. Journal of Cell Biology 63, 717748.

HADDOCK, B. A. \& GaRland, P. B. (1971). Effect of sulphate-limited growth on mitochondrial electron transfer and energy conservation between reduced nicotinamide adenine dinucleotide and the cytochromes in Torulopsis utilis. Biochemical Journal 124, I55-170.

HoffMANN, H. P. \& AVERs, C. J. (1973). Mitochondrion of yeast: ultrastructural evidence for one giant, branched organelle per cell. Science, New York, 181, 749-75I.

KaWAKami, N. (196I). Thread-like mitochondria in yeast cells. Experimental Cell Research 25, 179-181.

Keddie, F. M. \& Barajas, L. (1969). Three-dimensional reconstitution of Pityrosporum yeast cells based on serial section electron microscopy. Journal of Ultrastructure Research 29, 260-275.

KeyHan, E. (1972). Localisation cytochimique de la cytochrome oxydase chez la levure Candida utilis. Journal de Microscopie 15, 343-352.

KeYHANI, E. (1973). Morphological changes in yeast cell mitochondria grown at various copper concentrations. Experimental Cell Research 8I, 73-78.

Fig. 9. Thick section ( $\mu \mathrm{m}$ ) of chemostat-cultured glycerol-limited $C$. utilis sphaeroplast, stained with $3,3^{\prime}$-diaminobenzidine and osmium tetroxide. The accelerating voltage was $400 \mathrm{kV}$. A branched tubular mitochondrion is seen.

Fig. Io. Thick section (I $\mu \mathrm{m}$ ) of chemostat-cultured copper-deficient variant $C$. utilis cells, stained with lead citrate. The accelerating voltage was $1000 \mathrm{kV}$. The section shows a wider and more irregular mitochondrial structure than in Figs. 6 to 9.

Fig. I I. Lead citrate-stained thin section of a chemostat-grown sulphate-limited C. utilis cell, after an overnight recovery procedure without added sulphate (see Haddock \& Garland, 197I). The section shows a single branched mitochondrion running along the length of the cell.

Fig. I2. Thick section ( $\mu \mathrm{m}$ ) of a chemostat-cultured glycerol limited $C$. utilis cell stained with lead citrate. The accelerating voltage was $1000 \mathrm{kV}$. Numerous small mitochondrial structures are seen.

Fig. 13. Scanning transmission electron micrograph of a thick section $(0.5 \mu \mathrm{m})$ of a batch-cultured C. utilis sphaeroplast harvested in stationary phase from a glycerol-defined medium, sphaeroplasted and stained with $3,3^{\prime}$-diaminobenziodine and osmium tetroxide. The accelerating voltage was I00 kV. A single tubular mitochondrial structure can be discerned. 
KeyHaNi, E. \& ChaNCE, B. (197I). Cytochrome synthesis under copper-limited conditions in Candida utilis. FEBS Letters $17, \mathrm{I} 27-\mathrm{I} 32$.

Light, P. A. (1972). Mitochondrial effects of copper-limited growth of Torulopsis utilis. FEBS Letters I9, 319-322.

Light, P. A. \& Garland, P. B. (197I). A comparison of mitochondria from Torulopsis utilis grown in continuous culture with glycerol, iron, ammonium, magnesium or phosphate as the growth-limiting nutrient. Biochemical Journal 124, 123-1 24.

OSAFUNE, T. (1973). Three-dimensional structure of giant mitochondria dictyosomes and concentric lamellar bodies formed during the cell cycle of Euglena gracilis (z) in synchronous culture. Journal of Electron Microscopy 22, 5I-6I.

Osumi, M., Miwa, N., Teranishi, Y., Tanaka, A. \& Fukui, S. (1974). Ultrastructure of Candida yeasts grown on n-alkanes. Archiv für Mikrobiologie 99, 18I-20I.

ReYNolds, E. S. (1963). The use of lead citrate at high $\mathrm{pH}$ as an electron opaque stain in electron microscopy. Journal of Cell Biology 17, 209-212.

Rosen, D., Edelman, M., Galun, E. \& Danon, D. (1974). Biogenesis of mitochondria in Trichoderma viride: structural changes in mitochondria and other spore constituents during conidium maturation and germination. Journal of General Microbiology 83, 3I-49.

Seligman, A. M., Karnovsky, M. J., Wasserkrug, L. H. \& Hanker, J. S. (I968). Non-droplet ultrastructural demonstration of cytochrome oxidase activity with a polymerising osmiophilic reagent, diaminobenzidine. Journal of Cell Biology 38, I-14.

SPURR, A. R. (1969). A low-viscosity epoxy resin embedding medium for electron microscopy. Journal of Ultrastructure Research 26, 3I-43.

SUZUKI, K. (1969). Giant mitochondria: production in mice fed with cuprizone. Science, New York 163, 8I.

WeibulL, C. (1974). Studies on thick sections of microorganisms using electron microscopes working at accelerating voltages from 60 to $1000 \mathrm{kV}$. Journal of Ultrastructure Research 47, I06-I 14.

YotsuYANAGI, Y. (1955). Mitochondria and refractive granules in the yeast cell. Nature, London 176, 1208 1209. 